\title{
A Study of Ziegler-Natta Propylene Polymerization Catalysts by Spectroscopic Methods
}

\author{
Olga P. Tkachenko ${ }^{1}$, Alexey V. Kucherov ${ }^{1}$, Leonid M. Kustov ${ }^{1,2, *}$, Ville Virkkunen ${ }^{3}$, \\ Timo Leinonen ${ }^{3}$ and Peter Denifl ${ }^{4}$ \\ 1 Zelinsky Institute of Organic Chemistry, Russian Academy of Sciences, Leninsky Prosp. 47, \\ Moscow 119991, Russia; ot@ioc.ac.ru (O.P.T.); akuchero2004@yahoo.com (A.V.K.) \\ 2 National Science and Technology University MISiS, Leninsky prospekt 4, Moscow 119071, Russia \\ 3 Borealis Polymers Oy, P.O. Box 330, Porvoo F1-06101, Finland; Ville.Virkkunen@borealisgroup.com (V.V.); \\ Timo.Leinonen@borealisgroup.com (T.L.) \\ 4 Borealis Polyolefine GmbH, St. Peter-Strasse 25, Linz A-4021, Austria; Peter.Denifl@borealisgroup.com \\ * Correspondence: lmk@ioc.ac.ru or lmkustov@mail.ru; Tel.: +7-499-137-2935
}

Academic Editor: Jung Ho Je

Received: 26 February 2017; Accepted: 28 April 2017; Published: 3 May 2017

\begin{abstract}
Ziegler-Natta polymerization catalysts were characterized by a complex of surface- and bulk-sensitive methods (DRIFTS, XPS, ESR, and XAS = XANES + EXAFS). A diffuse-reflectance Fourier-transform IR spectroscopy (DRIFTS) study showed the presence of strong Lewis acid sites in different concentrations and absence of strong basic sites in the polymerization catalysts. X-ray photoelectron spectroscopy (XPS), electron-spin resonance (ESR), and (X-ray absorption near-edge structure (XANES) analysis revealed the presence of $\mathrm{Ti}^{4+}, \mathrm{Ti}^{3+}, \mathrm{Ti}^{2+}$, and $\mathrm{Ti}^{1+}$ species in the surface layers and in the bulk of catalysts. The samples under study differ drastically in terms of the number of ESR-visible paramagnetic sites. The EXAFS study shows the presence of a $\mathrm{Cl}$ atom as a nearest neighbor of the absorbing Ti atom.
\end{abstract}

Keywords: propylene polymerization catalysts; Fourier-transform IR spectroscopy; X-ray photoelectron spectroscopy; electron-spin resonance; XAS

\section{Introduction}

Solid olefin polymerization catalysts represent a very important class of materials. Information about the nature of active sites and spectroscopic information about the Ziegler-Natta polymerization catalysts are scarce. Far more information is available about the kinetics, preparation, and chemistry of the catalysts, including the mechanism of activation of the catalysts by aluminum-containing organic agents and the use of internal donors. Mixed oxides under study represent hybrid materials, which are known to be important for catalytic applications [1]. Several groups have demonstrated various techniques to unravel the state of titanium active species in these catalysts. Spectroscopic investigation of the $\mathrm{TiCl}_{4}-\mathrm{MgCl}_{2}$ systems was done [2]. Carbon monoxide was used as a probe molecule to test the surface sites in the $\mathrm{MgCl}_{2}$ support and in the $\mathrm{TiCl}_{4}-\mathrm{MgCl}_{2}$ catalysts of ethylene polymerization. It has been shown that a few types of Lewis acid sites (low-coordinated $\mathrm{Mg}$ ions) are present at the surface of the carrier, but they disappear after deposition of $\mathrm{TiCl}_{4}$ interacting with the surface sites of $\mathrm{MgCl}_{2}$.

The organic component of the Ziegler-Natta catalysts, i.e., internal donors at the surface of the Ti-Mg stereospecific propylene polymerization catalysts, was also studied by diffuse-reflectance Fourier-transform IR spectroscopy (DRIFT) [3]. Ethyl benzoate (EB) and di-n-butyl phthalate (DBP) were chosen as internal donors (ID). These molecules demonstrated a superposition band in the carbonyl region of the IR spectra that can be ascribed to perturbed ID molecules. Deconvolution of this band allowed the authors to distinguish three types of ID complexes in the case of EB; only one of 
these three was formed in the case of DBP. The data obtained were interpreted from the standpoint of the competition between ID and $\mathrm{TiCl}_{4}$ for the surface sites.

A model Ziegler-Natta catalyst on a $\mathrm{Pd}(111)$ substrate coated with the $\mathrm{MgCl}_{2}(001)$ layer was prepared in an ultra-high vacuum and studied using the electron-spin resonance (ESR) technique from the point of view of the formation of radical species during the ethylene polymerization process [4]. Particular attention was paid to the role of $\mathrm{AlR}_{3}$ moieties in the reaction, for example, via the interaction with $\mathrm{TiCl}_{4}$ :

$$
\mathrm{TiCl}_{4}+\mathrm{AlR}_{3} \rightarrow \mathrm{RTiCl}_{3} \rightarrow \mathrm{TiCl}_{3}+\mathrm{R}
$$

The authors also studied the effect of the so-called colored sites (defect sites, F-centers) in the development of the most effective catalyst. The formation of methyl radicals from $\mathrm{AlMe}_{3}$ was also detected by the low-temperature ESR spectroscopy. Furthermore, ethyl radicals were detected as a result of the reaction of methyl radicals with $\mathrm{AlMe}_{3}$. However, the authors, surprisingly, did not find any $\mathrm{Ti}^{3+}$ species in the ESR spectra.

One more type of model Ziegler-Natta polymerization catalysts was prepared by spin-coating on a flat $\mathrm{SiO}_{2} / \mathrm{Si}(100)$ support [5]. XPS analysis of such a catalyst showed the presence of $\mathrm{Ti}^{3+}$ species after the thermal treatment of the system at $723 \mathrm{~K}$, when a significant part of the chlorine is removed.

Yet another approach to study the Ziegler-Natta polymerization catalysts was reported [6]. The use of high-resolution electron microscopy in the investigation of the ethylene polymerization catalysts allowed the authors to discriminate the $\alpha-\mathrm{TiCl}_{3}$ phase, which was destroyed rapidly after exposure to ambient air. It should be noted, in view of our further discussion, that such a phase would not reveal any $\mathrm{Ti}^{3+}$ paramagnetic centers visible in ESR.

Quite a detailed study of the model Mg-Ti catalysts prepared by gas phase deposition of the components onto the Au polycrystalline foil under UHV conditions (pressures around $1.3 \times 10^{-5} \mathrm{~Pa}$ ) is reported in [7]. The authors found the formation of a $\mathrm{TiCl}_{2}$ layer onto the $\mathrm{TiCl}_{4}$ layer. Addition of $\mathrm{AlEt}_{3}$ into the system leads to the formation of mixed $\mathrm{TiR}_{n} \mathrm{Cl}_{4-n}$ complexes. Again, no sign of the presence of $\mathrm{TiCl}_{3}$ was found in the spectra. These model catalysts were tested in ethylene and propylene polymerization. The fraction of $\mathrm{Ti}^{4+}$ species in the total Ti content after the treatment with $\mathrm{AlEt}_{3}$ decreased gradually from 0.6 to 0.2 when increasing the $\mathrm{AlEt}_{3}$ exposure (measured in Langmuir units).

There are a few papers in which studies were carried out using not model, but real olefin polymerization catalysts $[8,9]$. The authors investigated the interaction between the $\mathrm{EB} / \mathrm{TiCl}_{4} / \mathrm{MgCl}_{2}$ catalyst and an $\mathrm{AlR}_{3}$ co-catalyst with the goal of finding a relationship between the degree of titanium reduction and the activity in the olefin polymerization reaction. They observed the dependence of the $\mathrm{Ti}^{2+}$ and $\mathrm{Ti}^{3+}$ contents determined by redox titration on the $\mathrm{Al} / \mathrm{Ti}$ ratio, activation temperature, and aging time or reaction time. For instance, for the catalytic systems activated at $70{ }^{\circ} \mathrm{C}$ for $2 \mathrm{~h}$ at the $\mathrm{Al} / \mathrm{Ti}$ ratio of 200, the following distribution was revealed from the XPS data: $\mathrm{Ti}^{4+}: \mathrm{Ti}^{3+}: \mathrm{Ti}^{2+}=9: 31: 60$, i.e., even after severe reduction conditions, a portion of titanium remains in the non-reduced state. The conclusion has been drawn that for ethylene polymerization both $\mathrm{Ti}^{3+}$ and $\mathrm{Ti}^{2+}$ species seem to contribute to the overall activity, whereas in the case of propylene conversion the major contribution is likely made by the higher oxidation states $\left(\mathrm{Ti}^{4+}\right.$ and $\left.\mathrm{Ti}^{3+}\right)$, with the latter being most active in the title process. Similar conclusions were made in the second paper of the Italian team [9].

The Japanese group $[10,11]$ reported on the interaction of the $\mathrm{TiCl}_{4} / \mathrm{MgCl}_{2}$ catalyst with an internal donor and found that the position of the Ti XPS peak does not change when varying the nature of the internal donor and the preparation method. The peak position was, however, different for a model $\mathrm{TiCl}_{4}$-ester complex, which indicated that such a complex is not formed at the surface, and titanium most probably was present in the reduced state. Thus, the authors concluded that the internal donor could only influence the state of titanium via the intermediacy of $\mathrm{MgCl}_{2}$.

ESR spectroscopy is an informative method in the physicochemical study of Ti catalysts for olefin polymerization. However, in spite of the frequent use of ESR in monitoring the formation and role of paramagnetic sites in polymerization reactions, a lot of conflicting data are reported 
about the nature of catalytically active sites and active species formed [12-20]. Both the influence of the $\mathrm{Ti}$ oxidation state on the catalyst properties and the catalytic activity of cationic $\mathrm{Ti}^{3+}$ complexes are mainly claimed $[12,13,17,18]$. In a study of the copolymerization of styrene and ethylene [14], ESR spectroscopic analysis combined with copolymerization kinetics results suggested the presence of a $\mathrm{Ti}^{4+}$ active center that is responsible for the formation of polyethylene, a $\mathrm{Ti}^{3+}$ species active in the syndiospecific polymerization of styrene, and, moreover, the presence of a third intermediate contributing to the promotion of the copolymerization of styrene with ethylene. The formation of paramagnetic $\mathrm{Ti}_{2}{ }^{7+}$ pairs is discussed [8]. In the ESR study of the $\mathrm{Cp}^{*} \mathrm{TiMe}_{3} / \mathrm{B}\left(\mathrm{C}_{6} \mathrm{~F}_{5}\right)_{3}$ system, it was shown that a small portion $(<0.01 \%)$ of titanium is occasionally present during polymerization as a complex of $\mathrm{Ti}^{3+}$, thereby suggesting that a contribution of the $\mathrm{Ti}^{3+}$ species to the catalytic process is unlikely. Different $\mathrm{Ti}^{4+}$ species are identified using ${ }^{13} \mathrm{C}$ - and ${ }^{1} \mathrm{H}-\mathrm{NMR}$ spectroscopy, and the portion of ESR-active $\mathrm{Ti}^{3+}$ species in the $\mathrm{Cp}^{*} \mathrm{TiCl}_{3} / \mathrm{MAO}$ system is evaluated as $<1 \%$ [9].

Thus, most studies published so far are related to the model catalysts and only the XPS method was used in studying the Ziegler-Natta polymerization catalysts. In this paper, we present details of characterization of the Ziegler-Natta polymerization catalysts by a complex of surface- and bulk-sensitive methods (DRIFTS, XPS, ESR, and XAS).

\section{Results and Discussion}

\subsection{DRIFTS}

Figure 1 presents the DRIFT spectra of the starting samples after evacuation and before the adsorption of probe molecules. The spectra of A carrier and B catalyst contain absorption bands assigned to the alkyl fragments, presumably formed at the stage of $\mathrm{MgCl}_{2}$ synthesis. The bands at 2963-2869 $\mathrm{cm}^{-1}$ can be attributed to $\mathrm{C}-\mathrm{H}$ stretching vibrations in $\mathrm{CH}_{2}$ group, whereas the bands at 1463-1381 $\mathrm{cm}^{-1}$ belong to the bending vibrations of the $\mathrm{CH}_{2}$ and $\mathrm{CH}_{3}$ groups [21].

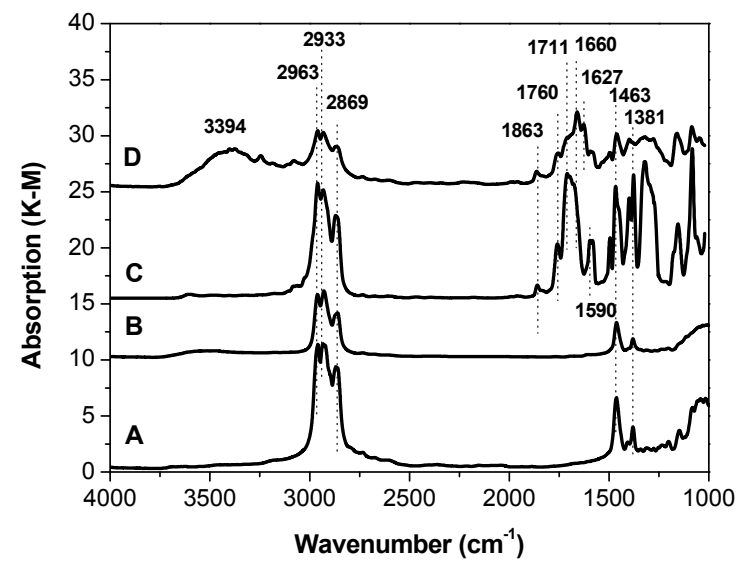

Figure 1. DRIFT survey spectra of propylene polymerization catalysts and carrier.

The IR spectra of the $C$ and $D$ catalysts are more complicated: they contain bands characterizing the presence of absorption due to the modification of the catalysts with internal donors and a reduction agent. In addition, in the spectrum of sample D, a broad absorption band centered at about $3400 \mathrm{~cm}^{-1}$ is observed [22]. This band may be assigned to the stretching vibrations of $\mathrm{OH}$ groups that are hydrogen-bonded with some ligands.

$\mathrm{OH}$ groups, most probably caused by a hydrolysis of the reduction agent $\left(\mathrm{Al}\left(\mathrm{C}_{2} \mathrm{H}_{5}\right)_{2} \mathrm{Cl}\right)$, are seen in sample D exclusively. The absorption band at $1627 \mathrm{~cm}^{-1}$ can be assigned to the complex of $\left(\mathrm{Al}\left(\mathrm{C}_{2} \mathrm{H}_{5}\right)_{2} \mathrm{Cl}\right)$ with carboxyl group of DEP [23]. In contrast to support (A) and catalyst (B) in IR spectra of $C$ and $D$ catalysts (Figure 2), a few absorption bands belonging to stretching vibrations of carbonyl groups were observed [24]. The doublet band at $1596-1583 \mathrm{~cm}^{-1}$ most probably belongs to 
$\left(\mathrm{TiCl}_{4} \mathrm{DEP}\right)_{2}$ and $\left(\mathrm{TiCl}_{4} \mathrm{DEHP}\right)_{2}$ surface complexes. The wide band near $1700 \mathrm{~cm}^{-1}$ may be assigned to $\mathrm{MgCl}_{2} \mathrm{DEP}$ and $\mathrm{MgCl}_{2} \mathrm{DEHP}$, whereas the band at $1660 \mathrm{~cm}^{-1}$ may be assigned to $\mathrm{AlEt}_{2} \mathrm{Cl} / \mathrm{DEHP}$ surface complexes. The bands at 1760 and $1860 \mathrm{~cm}^{-1}$ observed in spectra of catalysts $C$ and $\mathrm{D}$ are seemingly characteristic of physisorbed DEP and DEHP and/or their complexes with $\mathrm{MgCl}_{2}$, as proposed in the literature [25].

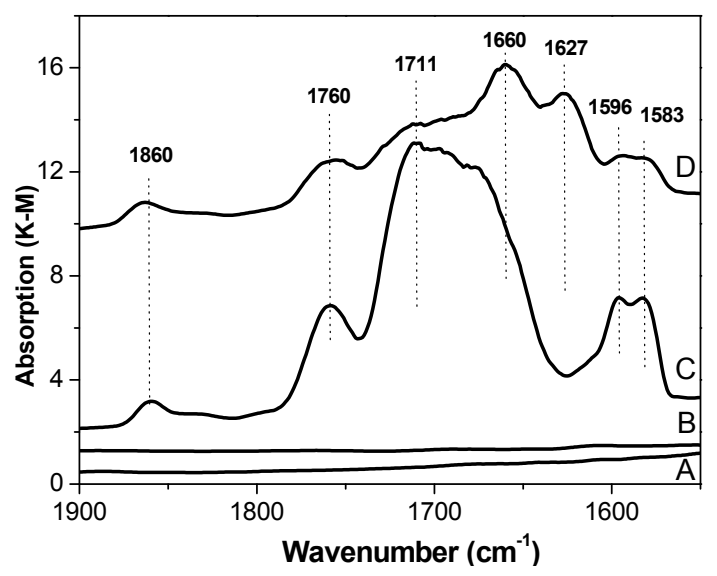

Figure 2. DRIFT spectra in the region of the carbonyl groups (internal donor) of the olefin polymerization catalysts and carrier.

The $\mathrm{CO}$ adsorption at room temperature produces no changes in the spectra. This effect was observed for all the samples under study and indicates that strong low-coordinated Lewis acid sites capable of adsorbing a weak base like the $\mathrm{CO}$ molecule are not present at the surface of the catalysts and carrier. Heating of the samples at $85^{\circ} \mathrm{C}$ in the presence of $\mathrm{CO}$ did not produce any changes in the IR spectra either.

The IR spectra of the catalysts measured after adsorption of $d_{3}$-acetonitrile are shown in Figure 3. It is seen that the adsorption of a stronger base (acetonitrile compared to $\mathrm{CO}$ ) leads to the appearance in the spectra of all the samples of the absorption bands characteristic for $\mathrm{C} \equiv \mathrm{N}$ stretching vibrations (2299-2306 $\left.\mathrm{cm}^{-1}\right)$ due to the formation of complexes with the so-called "shielded" Lewis acid sites (inaccessible to weak bases but accessible to strong bases due to the possibility of the latter changing the coordination sphere of the metal ions) [26-28]. In addition, the absorption bands attributed to unperturbed (physical adsorption) $\mathrm{C} \equiv \mathrm{N}$ and $\mathrm{C}-\mathrm{D}$ stretching vibrations $\left(2248-2245 \mathrm{~cm}^{-1}\right.$ and $2109 \mathrm{~cm}^{-1}$, respectively) are observed.

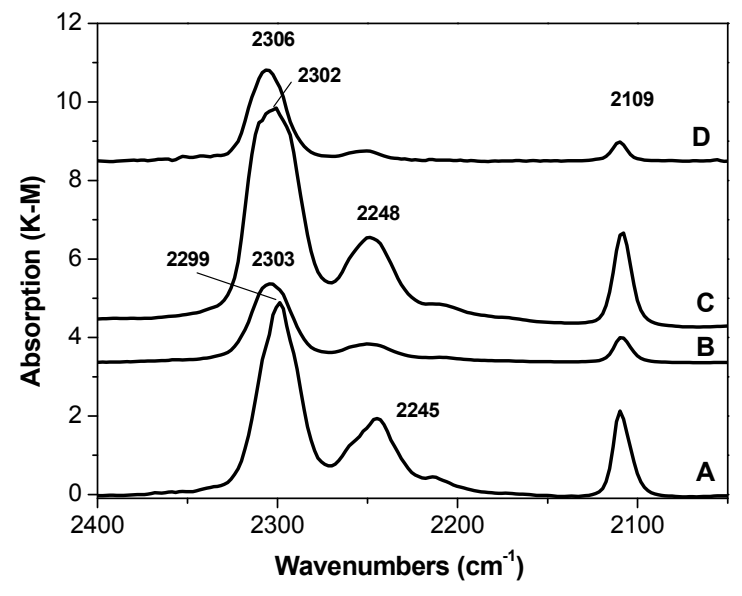

Figure 3. DRIFT spectra of $\mathrm{CD}_{3} \mathrm{CN}$ adsorbed at RT on the carrier and polymerization catalysts. 
Comparison of the spectra of adsorbed $\mathrm{d}_{3}$-acetonitrile shows that stronger Lewis acid sites are observed for sample $D$. The shift of the frequency of the $C \equiv N$ stretching vibrations for these catalysts is $53 \mathrm{~cm}^{-1}$ relative to the gas phase frequency $\left(2253 \mathrm{~cm}^{-1}\right)$. Somewhat weaker Lewis acid sites are present in the $B$ and $C$ catalysts, with the corresponding shifts being equal to $49-50 \mathrm{~cm}^{-1}$. The weakest Lewis acid sites (only $\mathrm{Mg}^{2+}$ cations) were found at the surface of the carrier (sample $\mathrm{A}$ ). The $\mathrm{C} \equiv \mathrm{N}$ frequency shift for this sample is $46 \mathrm{~cm}^{-1}$. It should be noted that sample $C$ is most likely characterized by a rather broad distribution of the Lewis acid sites of different strengths, since a broadened absorption band is observed in the IR spectrum of this catalyst in the region of the $\mathrm{C} \equiv \mathrm{N}$ stretching vibrations. The Lewis acid sites in the $\mathrm{B}, \mathrm{C}$, and $\mathrm{D}$ samples are $\mathrm{Mg}^{2+}$ together with $\mathrm{Ti}^{n+}(n=4,3,2)$ cations.

Figure 4 shows the spectrum of sample D, measured after adsorption of $\mathrm{CDCl}_{3}$ at room temperature. The spectrum contains only one band attributed to the stretching vibrations of the $\mathrm{C}-\mathrm{D}$ bond at $2251 \mathrm{~cm}^{-1}$. This band is shifted by some $12 \mathrm{~cm}^{-1}$ to lower frequencies as compared to the $\mathrm{CDCl}_{3}$ frequency in the gas phase $\left(2263 \mathrm{~cm}^{-1}\right)$ [29]. From these data, it follows that no strong basic sites exist in this propylene polymerization catalyst; only moderate-strength sites are present in a significant concentration.

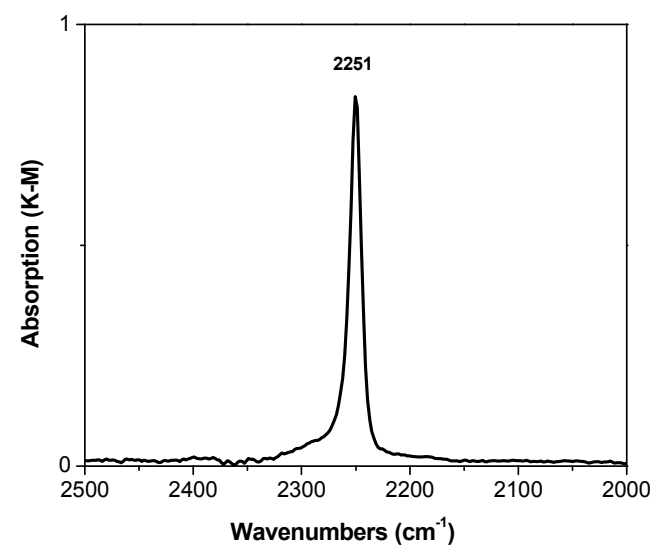

Figure 4. DRIFT spectrum of adsorbed $\mathrm{CCl}_{3} \mathrm{D}$ on D catalyst.

\subsection{XPS}

X-ray photoelectron spectra of the Ti $2 p$ region observed for the $\mathrm{B}, \mathrm{C}$, and D catalysts are shown in Figure 5. In Table 1, the positions and full widths at half maximum (FWHM) of the XPS peaks are collected, whereas Table 2 summarizes the surface atomic ratios.

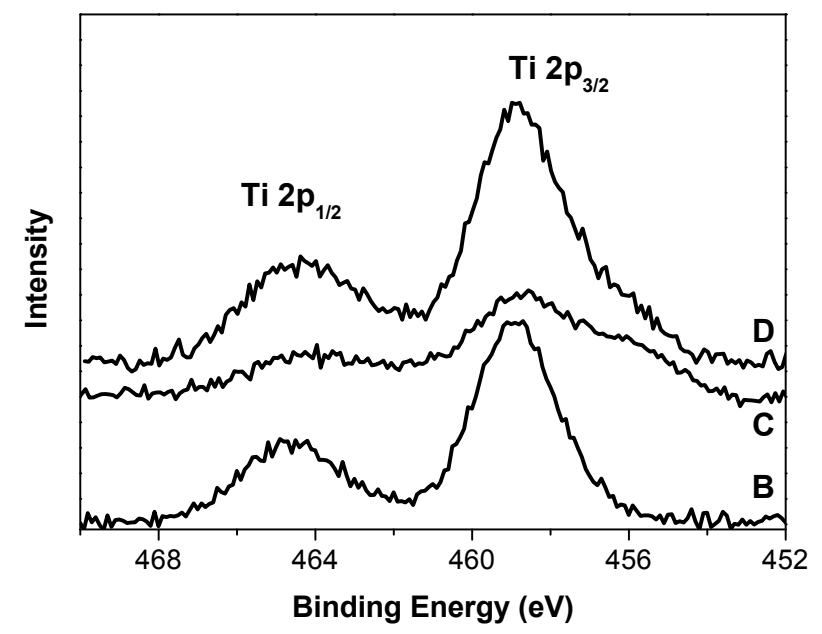

Figure 5. XP spectra of Ti $2 \mathrm{p}$ for the propylene polymerization catalysts. 
Table 1. XPS data of propylene polymerization catalysts and support.

\begin{tabular}{cccccc}
\hline \multicolumn{5}{c}{ Binding Energy (FWHM) (eV) } \\
\hline & $\mathrm{O} \mathrm{1s}$ & $\mathrm{Cl} 2 \mathrm{p}$ & $\mathrm{Mg} 2 \mathrm{p}$ & $\mathrm{Al} \mathrm{2p}$ & $\mathrm{Ti} 2 \mathrm{p}_{3 / 2}$ \\
$\mathrm{~A}$ & $532.7(3.1)$ & $199.8(3.4)$ & $51.6(2.8)$ & $75.0(3.1)$ & - \\
$\mathrm{B}$ & $532.4(3.3)$ & $199.7(3.2)$ & $52.0(3.0)$ & $74.8(3.3)$ & $458.9(2.3)\left(\mathrm{Ti}^{4+, 3+}\right)$ \\
$\mathrm{C}$ & $532.4(3.2)$ & $199.5(3.4)$ & $51.4(2.8)$ & $73.6(3.6)$ & $458.7(2.3)-60 \%\left(\mathrm{Ti}^{4+3}\right)$ \\
& & & & & $456.0(2.3)-40 \%\left(\mathrm{Ti}^{2+, 1+}\right)$ \\
$\mathrm{D}$ & $531.8(3.6)$ & $199.2(3.4)$ & $51.2(2.8)$ & $73.1(4.0)$ & $458.9(2.2)-80 \%\left(\mathrm{Ti}^{4+, 3+}\right)$ \\
& & & & & $456.3(2.2)-20 \%\left(\mathrm{Ti}^{2+, 1+}\right)$ \\
\hline
\end{tabular}

Table 2. XPS surface atomic composition.

\begin{tabular}{cccc}
\hline Sample & \multicolumn{3}{c}{ Atomic Ratio } \\
\hline & $\mathrm{Cl} / \mathrm{Mg}$ & $\mathrm{Al} / \mathrm{Mg}$ & $\mathrm{Ti} / \mathrm{Mg}$ \\
$\mathrm{A}$ & 0.78 & 0.75 & - \\
$\mathrm{B}$ & 0.90 & 0.32 & 0.33 \\
$\mathrm{C}$ & 1.02 & 0.22 & 0.06 \\
$\mathrm{D}$ & 1.02 & 0.49 & 0.23 \\
\hline
\end{tabular}

XPS survey spectra show the presence of $\mathrm{O}, \mathrm{C}, \mathrm{Mg}, \mathrm{Cl}, \mathrm{Ti}$, and $\mathrm{Al}$ atoms in the surface layers of the $\mathrm{B}, \mathrm{C}$, and D catalysts. The electronic state of oxygen in the carrier (A) and catalysts (B and C) is about the same $\left(\mathrm{E}_{\mathrm{b}} \mathrm{O} 1 \mathrm{~s}=532.4-532.7 \mathrm{eV}\right)$. The FWHM of XPS peaks is almost identical $(3.1-3.3 \mathrm{eV})$ (Table 1). It should be noted that the $\mathrm{O} 1 \mathrm{~s}$ line in the XP spectra of sample $\mathrm{D}$ is broadened compared to sample $\mathrm{C}$ ( $3.6 \mathrm{vs} .3 .2 \mathrm{eV}$ ) and $\mathrm{E}_{\mathrm{b}} \mathrm{O}$ 1s is lower ( $\left.531.8 \mathrm{vs} .532 .4 \mathrm{eV}\right)$. This fact can be accounted for by the presence of different oxygen-containing internal donors at the surface of these two catalysts and the presence of water in sample D (see Figures 1 and 2).

The electronic state of chlorine is about the same in samples $A$ and $B\left(E_{b} C l 2 p=199.7-199.8 \mathrm{eV}\right)$. A somewhat higher electron density on the chlorine atoms was found in samples $C$ and $D\left(E_{b} C l\right.$ $2 \mathrm{p}=199.2-199.5 \mathrm{eV})$. The FWHM of the $\mathrm{Cl} 2 \mathrm{p}$ line is the smallest for sample $\mathrm{B}(3.2 \mathrm{eV})$, whereas for the other samples it was $3.4 \mathrm{eV}$.

Figure 6 demonstrates XP spectra in the region of $\mathrm{Al} 2 \mathrm{p}, \mathrm{Mg} 2 \mathrm{~s}$, Ti 3s, and $\mathrm{Mg} 2 \mathrm{p}$ electrons. The XPS lines of the $\mathrm{Al} 2 \mathrm{p}$ and $\mathrm{Mg} 2 \mathrm{~s}$ electrons overlap. The presence of titanium compounds in sample $\mathrm{B}$ leads to a change in the state of magnesium and aluminum compared with the carrier (sample A) containing these two components only. The binding energy of $\mathrm{Mg} 2 \mathrm{p}$ electrons increases, whereas that of $\mathrm{Al} 2 \mathrm{p}$ electrons decreases (Table 1). The presence of the internal donors in two other samples results in an electron density increase on $\mathrm{Mg}$ in the $\mathrm{C}$ and $\mathrm{D}$ samples $\left(\mathrm{E}_{\mathrm{b}} \mathrm{Mg} 2 \mathrm{p}=51.4-51.2 \mathrm{eV}\right)$. The binding energy of $\mathrm{Al} 2 \mathrm{p}$ electrons in both $\mathrm{C}$ and $\mathrm{D}$ samples decreases significantly as well. In addition, the $\mathrm{Al}$ $2 p$ line in the XP spectra of samples $C$ and $D$ is wide $(3.6-4.0 \mathrm{eV})$, while the width of the $\mathrm{Mg} 2 \mathrm{p}$ line is nearly the same $(2.8-3.0 \mathrm{eV})$.

It is seen in Figure 5 that the Ti $2 p$ line in the XP spectrum of sample B represents a narrow symmetric doublet with symmetrical components. On the contrary, the components of the Ti $2 p$ doublet in the spectra of two other samples are broadened. The Ti 2 p spectrum of sample $C$ explicitly demonstrates the additional inhomogeneity as shoulders in the region of lower binding energies. From the position of the maxima of the Ti $2 \mathrm{p}_{3 / 2}$ line in the spectra of the catalysts and the width of these lines we assume the presence of one or several states of titanium in the surface layers of the catalysts available for XPS analysis. In the literature, there are no significant differences in the binding energies (B.E.) of the Ti $2 \mathrm{p}_{3 / 2}$ lines in the XP spectra of complexes of $\mathrm{Ti}^{4+}\left(\right.$ or $\left.\mathrm{Ti}^{3+}\right)$ and solid compounds containing $\mathrm{Ti}^{4+}\left(\right.$ or $\left.\mathrm{Ti}^{3+}\right)[8,10,30-32]$. The position and shape of the Ti $2 \mathrm{p}_{3 / 2}$ line in the XP spectrum of sample $\mathrm{B}\left(\mathrm{E}_{\mathrm{b}}=458.9 \mathrm{eV}\right)$ and its FWHM $(2.3 \mathrm{eV})$ (Table 2) show that both Ti states may be possible. Further differentiation by ESR study (see below) allowed us to identify the state of titanium in this sample as $\mathrm{Ti}^{3+}$. The mathematical treatment of Ti 2p spectra of samples C and D (Figures S1 and S2, supporting information) shows that titanium in this oxidation state is also present at the surface layers of $C$ (about 
$60 \%$ ) and $\mathrm{D}$ (about $80 \%$ ) samples. The rest of titanium in the $\mathrm{C}$ and $\mathrm{D}$ samples is identified as a Ti species with a lower positive charge compared to sample B. Part of titanium can be identified as $\mathrm{Ti}^{2+}$ according to [33]. In addition, the Ti centers in sample $C$ have a large electron density. The higher B.E. of the Ti $2 p_{3 / 2}$ lines found in the XP spectra of sample D might be caused, according to [9], by the presence of $\mathrm{H}_{2} \mathrm{O}$ in this sample. The presence of water at the surface of this sample was confirmed by DRIFT (see Figure 1).

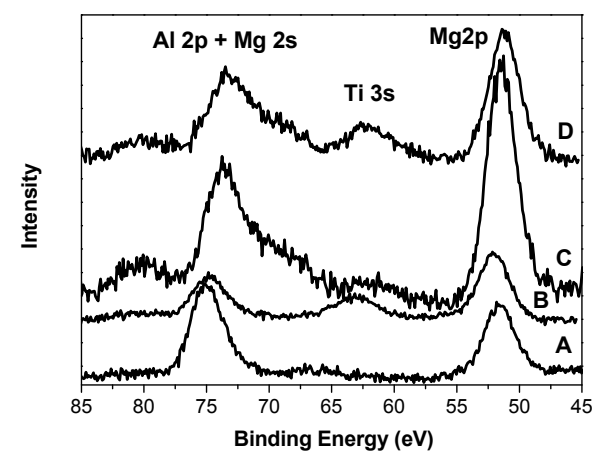

Figure 6. XP spectra of the $\mathrm{Al} 2 \mathrm{p}-\mathrm{Mg}$ 2s-Ti 3s-Mg 2p electron levels in catalysts and carrier.

Table 2 summarizes the atomic ratios of the components with respect to magnesium, which is present in all these samples. There is some chlorine deficit at the surface of the starting $\mathrm{MgCl}_{2}$ sample (the $\mathrm{Cl} / \mathrm{Mg}$ ratio is equal to 0.78 instead of 2). It is seen that the atomic ratio $\mathrm{Ti} / \mathrm{Mg}$ is higher in the surface layers of the $\mathrm{MgCl}_{2}+\mathrm{TiCl}_{4}$ sample (B) as compared to the other samples under study.

\subsection{ESR}

In ESR testing of samples, paramagnetic $\mathrm{Ti}^{3+}$ ions located both on the surface and in the volume of catalyst particles are detected. However, peculiarities of sample reoxidation or interactions with ligand molecules allow us to draw some conclusions about the surface/bulk location of paramagnetic sites. The starting sample B demonstrates a rather strong $\mathrm{Ti}^{3+}$ ESR signal at room temperature (Figure 7a). $\mathrm{CO}$ adsorption causes only a minor change in the signal shape (Figure $7 \mathrm{~b}$ ).

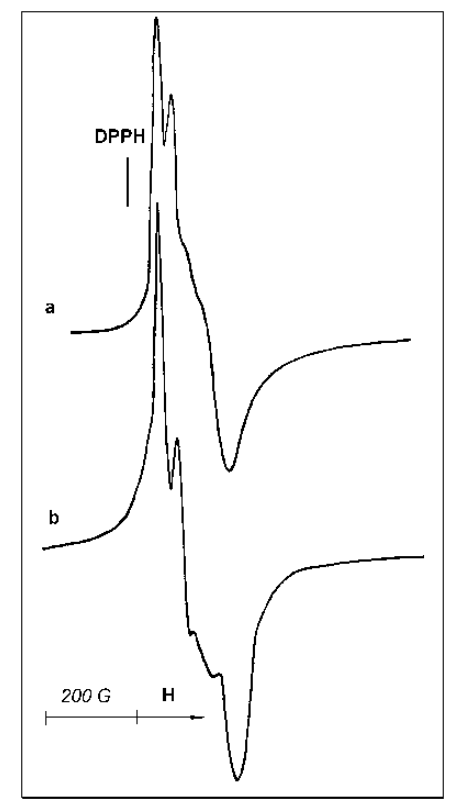

Figure 7. ESR spectra, taken at $20^{\circ} \mathrm{C}$, of sample B: (a) initial; (b) after CO adsorption at $1.3 \mathrm{kPa}$. 
Acetonitrile adsorption on this catalyst is accompanied by more pronounced changes in the signal shape and asymmetry (Figure 8a), demonstrating a measurable transformation of the paramagnetic site symmetry. Subsequent evacuation of the sample at $50{ }^{\circ} \mathrm{C}$ does not lead to the restoration of the parent ESR signal (Figure 7a) but causes only minor changes of the signal shape (Figure 8b), confirming that acetonitrile molecules are strongly bonded in the complex formed.

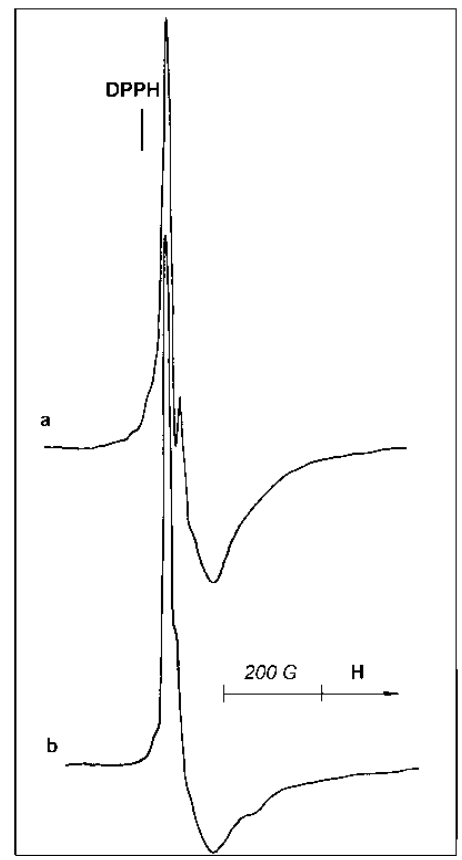

Figure 8. ESR spectra, taken at $20^{\circ} \mathrm{C}$, of sample B: (a) with acetonitrile adsorption at $12 \mathrm{kPa}$; (b) after evacuation at $50{ }^{\circ} \mathrm{C}$ for $30 \mathrm{~min}$.

Interaction of sample B with air is accompanied by the appearance of a very weak narrow ESR signal at $\mathrm{g}=2.003$, indicative of the formation of a small amount of $\mathrm{O}_{2}{ }^{-}$species. However, the low intensity of this signal casts into doubt the relationship between the newly formed $\mathrm{O}_{2}{ }^{-}$species and the existing $\mathrm{Ti}^{3+}$ paramagnetic sites. Moreover, the exposure of sample $\mathrm{B}$ to air does not cause an immediate disappearance of the ESR signal of paramagnetic Ti-sites; rather, it begins a slow decay of the signal (Figure 7a) that lasts for hours. Therefore, a considerable portion of ESR-visible $\mathrm{Ti}^{3+}{ }_{\text {-ions }}$ seems to be located inside the bulk of the active phase.

Two ESR signals in samples C and D are presented in Figure 9a,b, respectively. Comparison of these signals, taken at identical magnifications from two identical probes, illustrates a sharp difference in the concentration of paramagnetic sites in these catalysts.

No changes in the ESR signal (Figure $9 b$ ) take place as a result of CO adsorption on sample D. Rather insignificant irreversible transformation of the signal shape is observed after acetonitrile adsorption (Figure 9c). Surprisingly, the catalyst is very resistant to air exposure at $20^{\circ} \mathrm{C}$ : after $16 \mathrm{~h}$ of exposure to air, the ESR signal (Figure $9 \mathrm{~b}$ ) of paramagnetic Ti-sites retains $\sim 75 \%$ of the original intensity. Once more, a main part of paramagnetic $\mathrm{Ti}^{3+}$-sites detected in sample D by ESR is located in hindered positions inside catalyst particles and takes no part in the interaction with gas phase molecules.

Two ESR signals, taken at $-196{ }^{\circ} \mathrm{C}$, for samples B and D are presented in Figure 10a,b. It is clearly seen that the signals differ in their shape. Thus, the catalysts differ in the coordination/structure of the paramagnetic sites. Double integration of the two spectra permits us to conclude that the number of paramagnetic sites in sample $\mathrm{D}$ is maximal and exceeds the concentration of such centers in sample $B$ by a factor of $\sim 3.5$. 


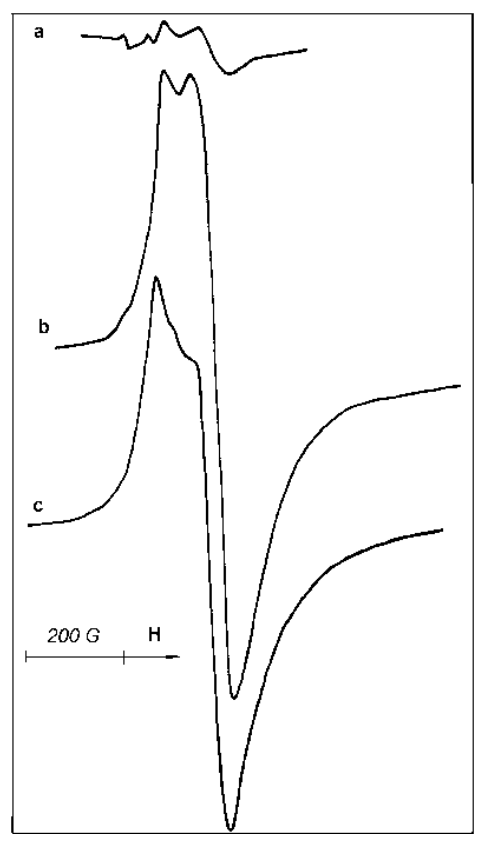

Figure 9. ESR spectra, taken at $20^{\circ} \mathrm{C}$, of samples $\mathrm{C}$ (a) and D: (b) initial; (c) after acetonitrile adsorption at $12 \mathrm{kPa}$.

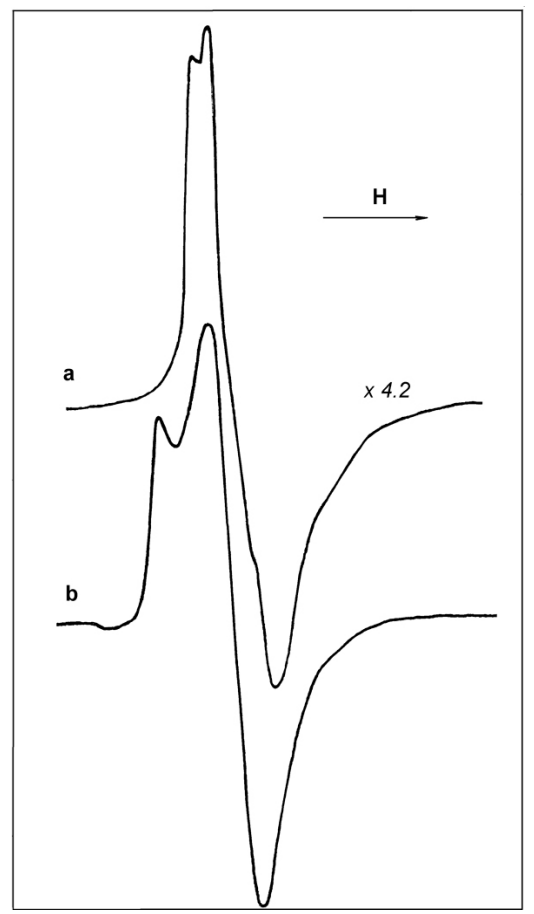

Figure 10. ESR spectra, taken at $-196^{\circ} \mathrm{C}$, of the initial samples $\mathrm{B}(\mathbf{a})$ and $\mathrm{D}(\mathbf{b})$.

The ESR spectrum of sample $\mathrm{D}$ is compared with a standard (frozen $\mathrm{TiCl}_{3}$ solution) taken as a reference for the evaluation of the number of "ESR-visible" $\mathrm{Ti}^{3+}$-sites in the samples (Figure 11). According to this evaluation, the number of paramagnetic centers in the catalyst D reaches $1-1.5 \%$ (wt \% of Ti). Taking into account that the total Ti concentration in the samples averages 2-4 wt \%, one can conclude that the considerable part $(\sim 50 \%)$ of $\mathrm{Ti}$ in $\mathrm{D}$ catalyst forms isolated paramagnetic sites. From the identity of the signal shapes, one can suppose that paramagnetic sites in this catalyst resemble isolated $\mathrm{Ti}^{3+}$ species in the frozen $\mathrm{TiCl}_{3}$ solution. 


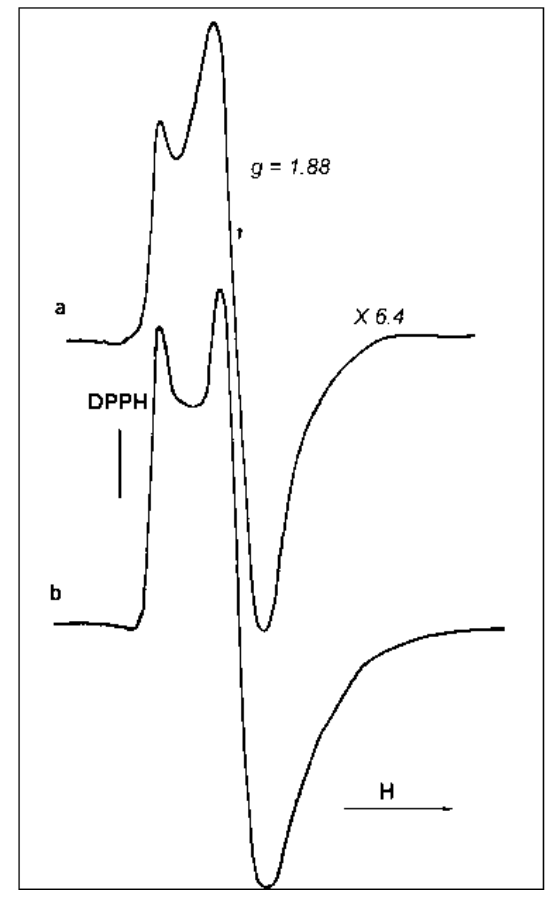

Figure 11. ESR spectra, taken at $-196{ }^{\circ} \mathrm{C}$, of sample $\mathrm{D}(\mathbf{a})$ and a frozen solution of $8.5 \mathrm{wt} \% \mathrm{TiCl}_{3}$ in concentrated $\mathrm{HCl}(\mathbf{b})$.

\subsection{XAS}

The Ti K-edge normalized XANES spectra of the catalysts and the reference samples are depicted in Figure 12. It is known that the pre-edge features of transition metals are related to the coordination number, oxidation state of adsorbing atom, and symmetry of the adsorbing atom site [34-36]. The pre-edge features in the spectra of the Ziegler-Natta catalysts are similar to each other, but they differ from those of reference compounds: $\mathrm{Ti}$-foil, $\mathrm{TiO}_{2}$ rutile, $\mathrm{TiCl}_{3}, \mathrm{TiCl}_{4}$, and $\mathrm{Ti}\left(\mathrm{C}_{3} \mathrm{H}_{7} \mathrm{O}\right)_{4}$. There is one narrow peak in the spectra of the Ziegler-Natta polymerization catalysts, in contrast to three of them in the $\mathrm{TiO}_{2}$ spectrum. There is one pre-edge peak in the spectrum of $\mathrm{TiCl}_{4}$ as well, but the pre-peak normalized height of the samples under study is around 0.25 , whereas the normalized height of the pre-peak for $\mathrm{TiCl}_{4}$ is about 0.55 (Figure S3, Supplementary Materials). Moreover, the pre-edge peak in the $\mathrm{TiCl}_{4}$ spectrum is located at a lower energy $(0.6 \mathrm{eV})$ compared with that in the spectra of the Ziegler-Natta catalysts under study. There are two pre-edge peaks in the spectrum of $\mathrm{TiCl}_{3}$ and the position of the main peak is shifted to a higher energy $(0.5 \mathrm{eV})$. There is one pre-edge peak in the spectrum of tetrabutoxy titanium located at the same energy as in the spectra of the Ziegler-Natta catalysts. Thus, the fingerprint approach indicates the absence of free $\mathrm{TiCl}_{4}$ tetrahedral clusters in the Ziegler-Natta polymerization catalysts. It indicates that the Ti species in these catalysts are definitely not $\mathrm{Ti}^{4+}$ ions surrounded by six oxygen atoms and not $\mathrm{Ti}^{3+}$ ions surrounded by three chlorine atoms.

The position of the Ti K-edge in the spectra of the polymerization catalysts is lower than that in $\mathrm{TiO}_{2}, \mathrm{TiCl}_{3}$, and $\mathrm{Ti}\left(\mathrm{C}_{3} \mathrm{H}_{7} \mathrm{O}\right)_{4}$ but similar to that in the spectrum of $\mathrm{TiCl}_{4}$. However, the shape of XANES and the height of the white line in the spectra of samples $\mathrm{C}$ and $\mathrm{D}$ differ from $\mathrm{TiCl}_{4}$. The spectrum of sample B differs from $\mathrm{TiCl}_{4}$ in the position and height of the pre-edge peak. This means that $\mathrm{Ti}$ in the studied Ziegler-Natta polymerization catalysts, perhaps, exists as a mixture of $\mathrm{Ti}^{4+}, \mathrm{Ti}^{3+}, \mathrm{Ti}^{2+}$, and $/$ or $\mathrm{Ti}^{1+}$ electronic states. These results are in good agreement with the conclusions drawn from the XPS data (see above).

Furthermore, one can deduce by analyzing the position of the Ti K-edge and the intensity of the white line that the Ti species in samples $C$ and D have, on average, a more electron-deficient character (surrounded by more electron-accepting neighbors), whereas sample B demonstrates a lower 
electron-deficient character (more electron-donating neighbors). The difference in the edge position can indicate the difference in the bond ionicity of Ti with nearest neighbors as well. In this case, the average bond ionicity is higher in the case of samples $\mathrm{C}$ and $\mathrm{D}$ and is lower in sample $\mathrm{B}$.

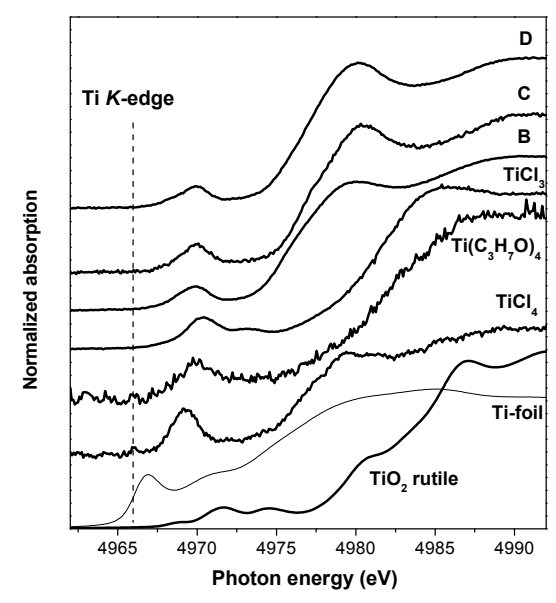

Figure 12. Normalized XANES spectra of the Ziegler-Natta polymerization catalysts and references.

The Fourier transformations of XAS oscillations for the Ziegler-Natta polymerization catalysts and references are presented in Figure 13. EXAFS oscillation of $\mathrm{Ti}\left(\mathrm{C}_{3} \mathrm{H}_{7} \mathrm{O}\right)_{4}$ reference compound is too noisy; therefore, FT is uncertain and is not shown. One peak is observed in the spectra of the B, C, and D catalysts. The position of this peak is near $2.2 \AA$ uncorrected distance in the spectrum of sample $B$, whereas it is near $1.8 \AA$ in the spectrum of the other two catalysts.

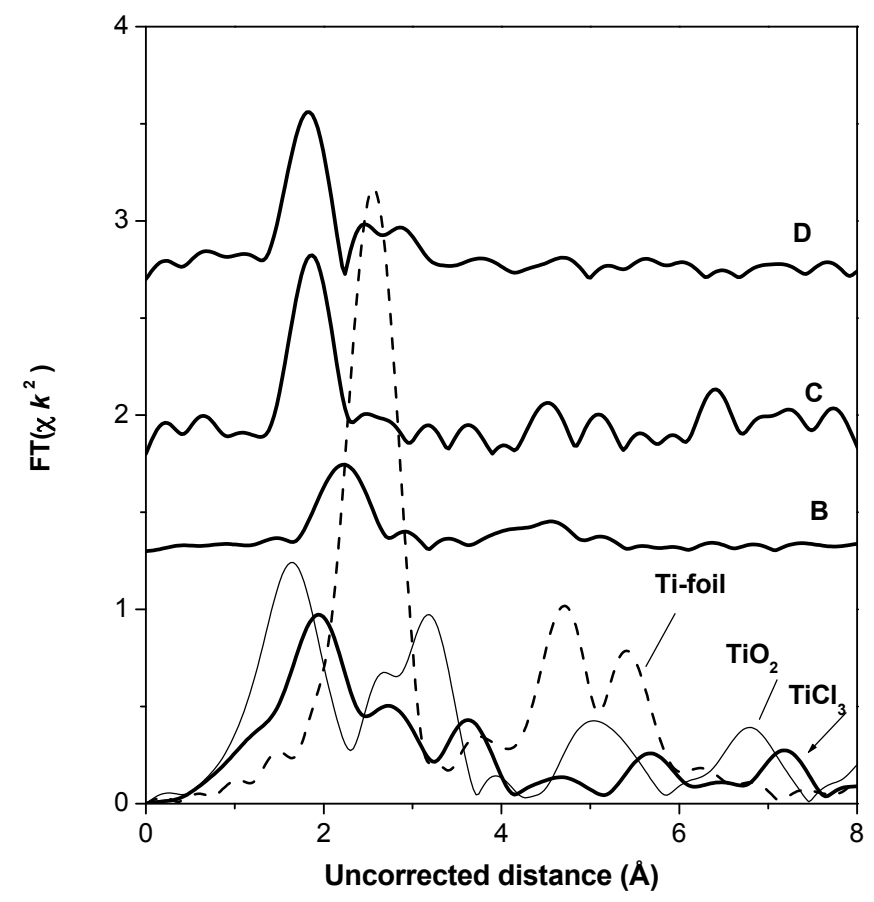

Figure 13. Fourier transformations of the EXAFS spectra of the Ziegler-Natta polymerization catalysts and references.

In the spectrum of $\mathrm{TiO}_{2}$, the first peak corresponds to the coordination shells containing $\mathrm{O}$ atoms at about $1.6 \AA$ uncorrected distance, whereas in the spectrum of $\mathrm{TiCl}_{3}$ the first peak corresponds to the coordination shell containing $\mathrm{Cl}$ atoms. 
The position of the first peak in the spectra of catalysts shows the possibility of the $\mathrm{Ti}-\mathrm{Cl}$ atomic pair presence in the first coordination shell. The first peak of the Ti FT EXAFS spectra was fitted in both $\mathrm{r}$ - and k-spaces with a one-shell model - a chlorine shell around the central absorbing titanium atom (Figure S4, Supplementary Materials). The results of the model fit are presented in Table 3. It is seen that the first shell contains one $\mathrm{Cl}$ atom at the real distance $2.25 \AA$ in sample $\mathrm{C}$. The real distance in the Ti-Cl atomic pair in sample D is considerably shorter $(2.23 \AA)$, than in sample B $(2.54 \AA)$.

Table 3. EXAFS data for the Ziegler-Natta polymerization catalysts.

\begin{tabular}{cccccc}
\hline Sample & Pair & $\mathbf{R}(\mathbf{A})$ & $\mathbf{C N}$ & $\boldsymbol{\sigma}\left(\mathbf{\AA}^{\mathbf{2}}\right)$ & $\boldsymbol{\Delta E}(\mathbf{e V})$ \\
\hline B & Ti-Cl & $2.539 \pm 0.006$ & $0.6 \pm 0.1$ & $0.006 \pm 0.001$ & $18.7 \pm 0.5$ \\
C & Ti-Cl & $2.253 \pm 0.005$ & $1.3 \pm 0.1$ & $0.008 \pm 0.001$ & $18.4 \pm 0.5$ \\
D & Ti-Cl & $2.229 \pm 0.008$ & $0.7 \pm 0.1$ & $0.005 \pm 0.001$ & $10.4 \pm 0.1$ \\
\hline
\end{tabular}

\section{Materials and Methods}

Four samples: $\mathrm{A}-\mathrm{MgCl}_{2}$ containing catalyst support; $\mathrm{B}-\mathrm{MgCl}_{2}$-based $\mathrm{TiCl}_{4}$ catalyst of ethylene polymerization; $\mathrm{C}$ and $\mathrm{D}-\mathrm{MgCl}_{2}$-based $\mathrm{TiCl}_{4}$ catalysts with the internal donor for propylene polymerization, were studied (Table 4).

Table 4. Catalyst and catalyst carrier samples.

\begin{tabular}{|c|c|c|c|c|}
\hline & \multirow{2}{*}{ Preparation Method } & \multicolumn{3}{|c|}{ Bulk Content (wt \%) } \\
\hline & & Ti & Al & $\mathrm{Mg}$ \\
\hline A & $\begin{array}{l}\mathrm{MgCl}_{2} \text { containing carrier material, prepared from magnesium alkoxide by } \\
\text { reacting it with ethylaluminium dichloride. Magnesium alkoxide was } \\
\text { prepared by reacting magnesium alkyl with a stoichiometric amount of alcohol. } \\
\text { Carrier material was prepared according to example } 3 \text { in patent [37]. }\end{array}$ & - & 0.6 & 0.63 \\
\hline B & $\begin{array}{l}\text { Catalyst was prepared from carrier sample A by reacting it with } \mathrm{TiCl}_{4} \text { and } \\
\text { washing with heptane as described in example } 3 \text { in patent [37]. }\end{array}$ & 8.0 & 1.3 & 12.7 \\
\hline $\mathrm{C}$ & $\begin{array}{l}\text { Ziegler-Natta catalyst prepared as described in example } 3 \text { in patent [38] with } \\
\text { diethyl phthalate (DEP) as an internal donor. }\end{array}$ & 1.96 & $0.1-0.2$ & 20.2 \\
\hline $\mathrm{D}$ & $\begin{array}{l}\text { Ziegler-Natta catalyst prepared as described in patent [39] in example } 5 . \\
\text { Bis(2-ethylhexyl)phthalate }(\mathrm{DEHP}) \text { was used as an internal donor and } \\
\text { diethylaluminium chloride }\left(\mathrm{Al}\left(\mathrm{C}_{2} \mathrm{H}_{5}\right)_{2} \mathrm{Cl}\right) \text { was used as a reduction agent. }\end{array}$ & 4.2 & $0.1-0.2$ & 13.1 \\
\hline
\end{tabular}

Diffuse-reflectance Fourier-transform infrared spectra of the polymerization catalysts were recorded at room temperature using a NICOLET "Protege" 460 spectrometer with a homemade diffuse-reflectance unit [40]. To obtain a satisfactory signal-to-noise ratio, 200 scans were collected per spectrum. The spectra were measured from 400 to $4000 \mathrm{~cm}^{-1}$ with a resolution of $4 \mathrm{~cm}^{-1}$. The powdered samples of the catalysts were placed in the ampoules using a glove box under a dried Ar atmosphere. The same quartz ampoules were used for ESR measurements. The probe molecules $\mathrm{CO}(1.3 \mathrm{kPa}), \mathrm{CD}_{3} \mathrm{CN}(12 \mathrm{kPa})$, and $\mathrm{CCl}_{3} \mathrm{D}(18.7 \mathrm{kPa})$, were adsorbed at room temperature. Before adsorption, non-activated samples were treated in a vacuum $(0.13 \mathrm{~Pa})$ for $20 \mathrm{~min}$ at ambient temperature.

Carbon monoxide and $\mathrm{d}_{3}$-acetonitrile were used as probe molecules for Lewis acid sites because they differ in their basicity and can differentiate between "exposed" Lewis acid sites, i.e., the sites with a low-coordinated cation exposing its electron vacancy for the interaction (like trigonal sites), and "shielded" Lewis acid sites, i.e., sites with a pseudo-saturated coordination sphere. In the latter case, a probe-molecule like $\mathrm{CD}_{3} \mathrm{CN}$ is capable of withdrawing the cation from its coordination sphere and increasing its coordination number. For instance, when we have a $\mathrm{MO}_{4}$ tetrahedron in which the metal ion is shielded by four oxygen atoms, adsorption of a strong ligand (probe molecule) may result in the insertion of the fifth ligand into the coordination sphere of the metal [41]. In addition 
to probe molecules for acid sites and low-coordinated ions, we also used a probe molecule for basic sites, i.e., chlorine atoms of the metal chlorides forming the support and the catalyst, as well as oxygen atoms in the composition of the organic electron-donor modifiers used to activate the catalyst. For this purpose, the molecule of deuterated chloroform, as a weak acid, was chosen because of the presence of intense $\mathrm{CH}$ bonds on the initial catalyst surface before the adsorption of the probe molecule and thus the $\mathrm{CH}$-containing probes cannot be used for this purpose. Although the background in the region of $\mathrm{C}-\mathrm{D}$ vibrations was not good for reliable spectra measurement, we succeeded in collecting some data about the basic sites at the surface of the polymerization catalysts. Up to now we studied only the adsorption of $\mathrm{CHCl}_{3}$ on various solid carriers and catalysts and some representative shifts reflecting the measure of basicity due to the surface $\cdots \mathrm{O} \cdots \mathrm{H}-\mathrm{CCl}_{3}$ complexes are collected in Table 5 . Obviously, the stronger the $\mathrm{O} \cdots \mathrm{H}$ interaction in this complex, the larger the red shift of the $\mathrm{C}-\mathrm{H}$ stretching vibration, and vice versa. The corresponding shifts in the $\mathrm{C}-\mathrm{D}$ region are approximately equal to the value of the $\mathrm{C}-\mathrm{H}$ shift divided by $\sqrt{ } 2$ [42]. For sample $\mathrm{D}$ the spectrum was also taken after heating in $\mathrm{CO}$ at $85^{\circ} \mathrm{C}$ for $10 \mathrm{~min}$. For the same sample, adsorption of $\mathrm{CDCl}_{3}$ at room temperature was carried out.

Table 5. Representative frequency shifts after adsorption of $\mathrm{CHCl}_{3}$ on different solid materials [24].

\begin{tabular}{cc}
\hline Material & Frequency Shift $\left(\mathbf{c m}^{\mathbf{- 1}}\right)$ \\
\hline Na-mordenite (zeolite) & 10 \\
Na-Y zeolite & 24 \\
$\mathrm{ZrO}_{2}$ & 29 \\
$\mathrm{MgO}$ & 29,64 \\
$\mathrm{Na}-\mathrm{X}$ zeolite & 42 \\
$\mathrm{Cs}_{2} \mathrm{CO}_{3} / \mathrm{NaX}$ zeolite & 52 \\
Polymerization catalysts & $14-15^{*}$ \\
\hline
\end{tabular}

${ }^{*}$ Calculated from the $\mathrm{C}-\mathrm{D}$ frequency.

XPS spectra were recorded using a XSAM 800 spectrometer with Mg K $\alpha$ X-ray (1253.6 eV) source. The base pressure in the XPS chamber was about $1.3 \times 10^{-5} \mathrm{~Pa}$. The spectrometer was calibrated using the binding energy $\left(\mathrm{E}_{\mathrm{b}}\right)$ of the $\mathrm{Au} 4 \mathrm{f}_{7 / 2}$ level $=84.0 \mathrm{eV}$ and Ni $2 \mathrm{p}_{3 / 2}=852.7 \mathrm{eV}$. Survey spectra were collected between 20 and $1130 \mathrm{eV}$. Detailed spectra were recorded for the region of C 1s, O 1s, $\mathrm{Mg} 2 \mathrm{p}, \mathrm{Cl} 2 \mathrm{p}, \mathrm{Al} 2 \mathrm{p}$, and Ti $2 \mathrm{p}$ with a $0.1 \mathrm{eV}$ step. The $\mathrm{C} 1 \mathrm{~s}$ line at $285.0 \mathrm{eV}$ was used for energy calibration. The $\mathrm{Mg} 2 \mathrm{p}$ line $(51.6 \mathrm{eV})$ was used as an internal standard for the carrier. The surface atomic composition and atomic ratio were calculated after a Shirley type background subtraction [43] by dividing the peak area by the photo-ionization cross-sections [44]. The experimental Ti $2 p$ spectra have been deconvoluted in a series of mixed Gaussian-Lorentzian shape contributions.

ESR spectra were taken in the $X$-band $(\lambda \cong 3.2 \mathrm{~cm})$ at $20^{\circ} \mathrm{C}$ and $-196{ }^{\circ} \mathrm{C}$ using a reflecting-type ESR spectrometer equipped with a $4104 \mathrm{OR}$ cavity and quartz Dewar vessel. The ESR signals were registered in the absence of saturation in the field range of 2000-4000 G. The Excel program was used for spectra processing (baseline correction, double integration). DPPH and a frozen solution of $8.5 \mathrm{wt} \%$ $\mathrm{TiCl}_{3}$ in concentrated $\mathrm{HCl}$ were used as standards for $\mathrm{g}$-factor calculation and quantitative $\mathrm{Ti}^{3+} \mathrm{ESR}$ analysis, respectively.

The samples of catalysts were inserted into identical quartz ampoules in a glove box for combined use in ESR study and DRIFT spectroscopy. The amount of the sample in the cylindrical ESR part of the ampoule ( $3.5 \mathrm{~mm}$ in diameter) exceeded the volume of the sample in the resonator $(>30 \mathrm{~mm}$ height). ESR spectra were registered at $20^{\circ} \mathrm{C}$ and $-196^{\circ} \mathrm{C}$ immediately after the DRIFT measurements. Next, closed ampoules were connected to the adsorption setup and the samples were treated with $\mathrm{CO}$ or $\mathrm{d}_{3}$-acetonitrile. Then DRIFT and ESR measurements at $20^{\circ} \mathrm{C}$ and $-196^{\circ} \mathrm{C}$ were repeated. The solution of $8.5 \mathrm{wt} \% \mathrm{TiCl}_{3}$ in $\left(30 \% \mathrm{HCl}+\mathrm{H}_{2} \mathrm{O}\right)$ was used as a standard for the comparative evaluation of the "ESR-visible" fraction of $\mathrm{Ti}^{3+}$ in the samples. Double integration of the ESR spectrum of this standard provided the absolute value for comparison with double integrals of the signals under study. 
The shape of the ESR lines does not play any role, and the spectra simulation was not required. For the sake of accuracy, the series of the samples were measured consecutively, with ampoules placed in the same position inside the ESR resonator one after another.

X-ray absorption spectra (Ti K-edge at $4966 \mathrm{eV}$ ) were measured at HASYLAB E4 station (DESY, Hamburg, Germany). The X-ray beam was monochromatized with Si(111) double crystal detuned to $50 \%$ of the maximum intensity to avoid higher harmonics contamination of the monochromatized beam. The spectra $\mu(\mathrm{E})$ were measured at $-196{ }^{\circ} \mathrm{C}$ in a transmission mode using ionization chambers. The spectrum of Ti metal foil (between the second and third ionization chambers) was recorded at the same time for energy calibration purposes.

Special care was taken to avoid air contamination. For sample preparation, a mixture of about $10 \mathrm{mg}$ of the catalyst (the optimum weight to maximize the signal-to-noise ratio) and $20 \mathrm{mg}$ of polyethylene powder (spectrophotometric grade, Aldrich) as a binding agent was pressed into a 13-mm diameter pellet in a glove box (a dried Ar atmosphere) and completely wrapped in Kapton polyimide tape with silicone adhesive. The aim of dilution was to provide transmission of approximately $30 \%$ of the beam. However, a good signal to noise ratio was not always achieved, because a significant portion of the beam absorption came from other atoms, such as $\mathrm{Mg}, \mathrm{Al}, \mathrm{Si}$, and $\mathrm{Cl}$. Reference spectra for $\mathrm{Ti}^{0}$ and $\mathrm{Ti}^{4+}$ oxidation states were recorded using standard reference samples (Ti-foil, $\mathrm{TiO}_{2}$ (rutile), $\mathrm{TiCl}_{3}, \mathrm{TiCl}_{4}$, and $\left.\mathrm{Ti}\left(\mathrm{C}_{3} \mathrm{H}_{7} \mathrm{O}\right)_{4}\right)$.

Data treatment was carried out with the software package VIPER [45]. In the spectra of the absorption coefficient $\mu$, a Victorian polynomial was fitted to the pre-edge region for background subtraction. A smooth atomic background, $\mu_{0}(k)$, was evaluated using smoothed cubic splines. The radial distribution function $\mathrm{FT}\left[k^{2} \chi(k)\right]$ was obtained by Fourier transformation of $k^{2}$-weighted experimental function $\chi=\left(\mu(k)-\mu_{0}(k)\right) / \mu_{0}(k)$ performed with a Bassel window. For the determination of structural parameters, theoretical references calculated by the FEFF8.10 code were used [46]. Duplicate spectra were recorded to ensure data reproducibility.

\section{Conclusions}

We characterized a series of Ziegler-Natta polymerization catalysts by a complex of surface- and bulk-sensitive physical methods. DRIFTS study showed the presence of rather strong Lewis acid sites able to interact only with rather strong bases (acetonitrile) but not with weak molecules (CO). There are no strong basic sites in the polymerization catalysts; instead, only moderate-strength sites are present in a significant concentration. XPS analysis revealed the presence of $\mathrm{Ti}^{3+}$ and $\mathrm{Ti}^{1+}$ species in the surface layer of catalysts, with different ratios ranging from $100 \%$ of the $\mathrm{Ti}^{3+}$ species (sample $\mathrm{B}$ ) and $60 \%$ (sample C) to $80 \%$ (sample D). The total concentration of $\mathrm{Ti}$ in the surface layers diminishes in the following order: B > D > C. The samples under study differ drastically in terms of the total number (surface + bulk) of ESR-visible paramagnetic sites. The concentration of paramagnetic $\mathrm{Ti}^{3+}$-centers in the sample volume drops from $\sim 2 \mathrm{wt} \%$ Ti to 0 in the order D $>$ B $>>C$. The XANES study confirms the presence of a mixture of $\mathrm{Ti}^{4+}, \mathrm{Ti}^{3+}, \mathrm{Ti}^{2+}$, and $\mathrm{Ti}^{1+}$ electronic states of $\mathrm{Ti}$ in the bulk of the catalysts under study. The EXAFS study shows the presence of a $\mathrm{Cl}$ atom as the nearest neighbor of the absorbing $\mathrm{Ti}$ atom. Here the local structure (the $\mathrm{Ti}-\mathrm{Cl}$ distance and coordination number) of samples B, C, and D differs.

Supplementary Materials: The following supplementary materials are available online at www.mdpi.com/19961944/10/5/496/s1, Figure S1: Ti 2p XP spectrum deconvolution of sample C, Figure S2: Ti 2p XP spectrum deconvolution of sample D, Figure S3: Normalized pre-edge height vs. energy position for Ti K-pre-edge features, Figure S4: Model fits of Ti K EXAFS of sample B in k-space (a) and r-space (b).

Acknowledgments: A.V. Kucherov and L.M. Kustov acknowledge the financial support from the Ministry of Education and Science of the Russian Federation in the framework of the Increase Competitiveness Program of NUST «MISiS» (No. K1-2015-045) and HASYLAB (DESY, Hamburg, Germany) for X-ray beamtime (project I-20060226 EC).

Author Contributions: O.P. Tkachenko performed DRIFTS, XPS, and XAS experiments; A.V. Kucherov performed ESR experiments; L.M. Kustov conceived and designed the experiments; V. Virkkunen conceived and designed 
the experiments; T.L. and P.D. designed and analyzed the catalysts; O.P. Tkachenko and L.M. Kustov wrote the paper with help from A.V. Kucherov and V. Virkkunen.

Conflicts of Interest: The authors declare no conflicts of interest. The founding sponsors had no role in the design of the study; in the collection, analyses, or interpretation of data; in the writing of the manuscript, or in the decision to publish the results.

\section{References}

1. Ananikov, V.P.; Gordeev, E.G.; Egorov, M.P.; Sakharov, A.M.; Zlotin, S.G.; Redina, E.A.; Isaeva, V.I.; Kustov, L.M.; Gening, M.L.; Nifantiev, N.E. Challenges in the Development Organic and Hybrid Molecular Systems. Mendeleev Commun. 2016, 26, 365-374. [CrossRef]

2. Paukshtis, E.A.; Zakharov, V.A.; Makhtarulin, S.I.; Mikenas, T.B.; Vitus, E.N. Study of surface acidsites of highly dispersed magnesium chloride and titanium-magnesium catalysts of ethylene polymerization by diffuse-reflectance IR spectroscopy. Kinet. Katal. Rus. 1994, 35, 918-923.

3. Potapov, A.G.; Bukatov, G.D.; Zakharov, V.A. DRIFT study of internal donors in supported Ziegler-Natta catalysts. J. Mol. Catal. A Chem. 2005, 246, 248-254. [CrossRef]

4. Freund, H.-J.; Baumer, M.; Libuda, J.; Rupprechter, G.; Shaikhutdinov, S. Preparation and characterization of model catalysts: From ultrahigh vacuum to in situ conditions at the atomic dimension. J. Catal. 2003, 216, 223-235. [CrossRef]

5. Siokou, A.; Ntais, A. Towards the preparation of realistic model Ziegler-Natta catalysts: XPS study of the $\mathrm{MgCl}_{2} / \mathrm{TiCl}_{4}$ interaction with flat $\mathrm{SiO}_{2} / \mathrm{Si}(100)$. Surf. Sci. 2003, 540, 379-388. [CrossRef]

6. Higuchi, T.; Liu, B.; Nakatani, H.; Otsuka, N.; Terano, M. High resolution transmission electron microscopeobservation of $\alpha-\mathrm{TiCl}_{3}$. Appl. Surf. Sci. 2003, 214, 272-277. [CrossRef]

7. Magni, E.; Somorjai, G. Surface science study of model Ziegler-Natta catalysts. Surf. Sci. 1997, 377-379, 824-827. [CrossRef]

8. Fregonese, D.; Mortara, S.; Bresadola, S. Ziegler-Natta $\mathrm{MgCl}_{2}$-supported catalysts: Relationship between titanium oxidation states distribution and activity in olefin polymerization. J. Mol. Catal. A Chem. 2001, 172, 89-95. [CrossRef]

9. Fregonese, D.; Glisenti, A.; Mortara, S.; Rizzi, G.A.; Tondello, E.; Bresadola, S. $\mathrm{MgCl}_{2} / \mathrm{TiCl}_{4} / \mathrm{AlEt}_{3}$ catalytic system for olefin polymerisation: A XPS study. J. Mol. Catal. A Chem. 2002, 178, 115-123. [CrossRef]

10. Hasebe, K.; Mori, H.; Terano, M. X-ray photoelectron spectroscopy analysis for oxidation states of titanium chloride on the surface of Ziegler-Natta catalysts. J. Mol. Catal. A Chem. 1997, 124, L1-L3. [CrossRef]

11. Mori, H.; Endo, M.; Terano, M. Deviation of hydrogen response during propylene polymerization with various Ziegler-Natta catalysts. J. Mol. Catal. A Chem. 1999, 145, 211-220. [CrossRef]

12. Grassi, A.; Zambelli, A.; Laschi, F. Reductive decomposition of cationic half-titanocene (IV) complexes, precursors of the active species in syndiospecific styrene polymerization. Organometallics 1996, 15, 480-482. [CrossRef]

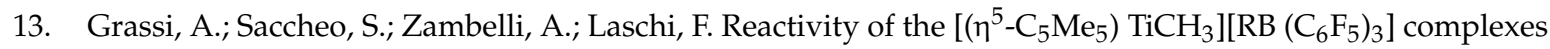
identified as active species in syndiospecific styrenepolymerization. Macromolecules 1998, 31, 5588-5591. [CrossRef]

14. Xu, G.; Lin, S.H. Titanocene-methylaluminoxane catalysts for copolymerization of styrene and ethylene: Synthesis and characterization of styrene-ethylene copolymers. Macromolecules 1997, 30, 685-693. [CrossRef]

15. Ewart, S.W.; Sarsfield, M.J.; Jeremic, D.; Tremblay, T.L.; Williams, E.F.; Baird, M.C. Ethylene and propylene polymerization by a series of highly electrophilic, chiral monocyclopentadienyltitanium catalysts. Organometallics 1998, 17, 1502-1510. [CrossRef]

16. Xu, J.; Zhao, J.; Fan, Z.; Feng, L. ESR study on $\mathrm{MgCl}_{2}$-supported half-titanocene catalyst for syndiospecific polymerization of styrene. Eur. Polym. J. 1999, 35, 127-132. [CrossRef]

17. Kim, H.J.; de Santa Maria, L.C. Polymerization of ethylene and propylene with homogeneous titanocene catalysts modified by trimethylsilanol. Eur. Polym. J. 1994, 30, 1295-1299. [CrossRef]

18. Bonoldi, L.; Abis, L.; Fiocca, L.; Fusco, R.; Longo, L.; Simone, F.; Spera, S. Monotitanocene catalysts: An ESR study of Ti(III) derivatives formed in presence of MAO and other organoaluminium compounds. J. Mol. Catal. A Chem. 2004, 219, 47-56. [CrossRef]

19. Anufrienko, V.F.; Guzman, I.S.; Zakharov, V.V.; Adrov, O.I.; Kucherov, A.V. ESR spectra of ${ }^{47}$ Ti-enriched titanium catalysts for polymerization. React. Kinet. Catal. Lett. 1991, 43, 75-79. [CrossRef] 
20. Bryliakov, K.P.; Semikolenova, N.V.; Zakharov, V.A.; Talsi, E.P. ${ }^{13}$ C-NMR study of Ti(IV) species formed by $\mathrm{Cp}^{*} \mathrm{TiMe}_{3}$ and $\mathrm{Cp}^{*} \mathrm{TiCl}_{3}$ activation with methylaluminoxane (MAO). J. Organomet. Chem. 2003, 683, 23-28. [CrossRef]

21. Kiselev, A.V.; Lygin, V.I. Infrared Spectra of Surface Compounds; Wiley: New York, NY, USA, 1975.

22. Davydov, A.A. Molecular Spectroscopy of Oxide Catalyst Surfaces; Wiley Interscience Publ.: Hoboken, NJ, USA, 2003.

23. Bache, Ø.; Ystenes, M. Stoihiometry and structure of $\mathrm{Al}\left(\mathrm{C}_{2} \mathrm{H}_{5}\right)_{3-\mathrm{n}} \mathrm{Cl}_{\mathrm{n}} / \mathrm{C}_{6} \mathrm{H}_{5} \mathrm{COOC}_{2} \mathrm{H}_{5}$ complexes $(n=0-2)$. J. Mol. Struct. 1997, 408-409, 291-299. [CrossRef]

24. Potapov, A.G.; Bukatov, G.D.; Zakharov, V.A. DRIFTS study of the interaction of the $\mathrm{AlEt}_{3}$ cocatalyst with the internal donor ethyl benzoate in supported Ziegler-Natta catalysts. J. Mol. Catal. A Chem. 2009, 301, 18-23. [CrossRef]

25. Kissin, Y.V.; Liu, X.; Pollick, D.J.; Brungard, N.L.; Chang, M. Ziegler-Natta catalysts for propylene polymerization: Chemistry of reactions leading to the formation of active centers. J. Mol. Catal. A Chem. 2008, 287, 45-52. [CrossRef]

26. Haney, M.A.; Franklin, J.L. Mass spectrometric determination of the proton affinities of various molecules. J. Phys. Chem. 1969, 73, 4328-4331. [CrossRef]

27. Medin, A.S.; Borovkov, V.Y.; Kazansky, V.B.; Pelmentschikov, A.G.; Zhidomirov, G.M. On the unusual mechanism of Lewis acidity manifestation in HZSM-5 zeolites. Zeolites 1990, 10, 668-673. [CrossRef]

28. Angell, C.L.; Howell, M.V. Infrared spectroscopic investigation of zeolites and adsorbed molecules. IV. Acetonitrile. J. Phys. Chem. 1969, 73, 2551-2554. [CrossRef]

29. Paukshtis, E.A.; Soltanov, R.I.; Yurchenko, E.N. Determination of the strength of aprotic acidic centers on catalyst surfaces from the IR spectra of adsorbed carbon monoxide. React. Kinet. Catal. Lett. 1981, 16, 93-96. [CrossRef]

30. Moulder, J.F.; Stickle, W.F.; Sobol, P.E.; Bomben, K.D. Handbook of X-ray PhotoelectronSpectroscopy; Perkin-Elmer: Eden Prairie, MN, USA, 1992.

31. Mayer, J.T.; Diebald, U.; Madley, T.E.; Garfunkel, E. Titanium and reduced titania overlayers on titanium dioxide(110). J. Electron Spectrosc. Relat. Phenom. 1995, 73, 1-11. [CrossRef]

32. Wright, S.C.; Walton, R.L.; Thompsett, D.; Fisher, J. Investigation of hydrothermal routes to mixed-metal cerium titanium oxides and metal oxidation state assignment using XANES. Inorg. Chem. 2004, 43, 2189-2196. [CrossRef] [PubMed]

33. Kissin, Y.V. Active centers in Ziegler-Natta catalysts: Formatin kinetics and structure. J. Catal. 2012, 292, 188-200. [CrossRef]

34. Yamamoto, T. Assignment of pre-edge peaks in K-edge X-ray absorption spectra of 3d transition metal compounds: Electric dipole or quadrupole? X-ray Spectrom. 2008, 37, 572-584. [CrossRef]

35. Cabaret, D.; Bordage, A.; Juhin, A.; Arfaoui, M.; Gaudry, E. First-principles calculations of X-ray absorption spectra at the K-edge of $3 d$ transition metals: An electronic structure analysis of the pre-edge. Phys. Chem. Chem. Phys. 2010, 12, 5619-5633. [CrossRef] [PubMed]

36. Shelimov, B.N.; Tolkachev, N.N.; Tkachenko, O.P.; Baeva, G.N.; Klementiev, K.V.; Stakheev, A.Y.; Kazansky, V.B. Enhancement effect of $\mathrm{TiO}_{2}$ dispersion over alumina on the photocatalytic removal of $\mathrm{NO} x$ admixtures from $\mathrm{O}_{2}-\mathrm{N}_{2}$ flow. J. Photochem. Photobiol. A Chem. 2008, 195, 81-88. [CrossRef]

37. Garoff, T.; Waldvogel, P.; Pesonen, K. Method for the Preparation of Olefin Polymerization Catalyst Support and an Olefin Polymerization Catalyst. Patent W02004/055068, 1 July 2004.

38. Garoff, T.; Leinonen, T.; Iiskola, E. A Procatalyst for Polymerization of Olefins Containing a Transesterification Product of a Low Alcohol and a Phthalic Acid Ester. Patent EP0591224, 11 February 1998.

39. Leinonen, T.; Denifl, P.; Poehler, H. Process for Preparing an Olefin Polymerization Catalyst Component with Improved High Temperature Activity. Patent W02004029112, 8 April 2004.

40. Kustov, L.M. New trends in IR-spectroscopic characterization of acid and basic sites in zeolites and oxide catalysts. Top. Catal. 1997, 4, 131-144. [CrossRef]

41. Klier, K. Reflectance spectroscopy as a tool of investigating dispersed solids and their surface. Catal. Rev. 1968, 1, 207-232. [CrossRef]

42. Kustov, L.M.; Zubkov, S.A.; Kazansky, V.B.; Bondar, L.A. Study of Broensted and Lewis acid sites in phosphates, silicates and silica gels with molecular sieve properties. Stud. Surf. Sci. Catal. 1991, 69, 303-311. 
43. Shirley, D.A. High-Resolution X-ray Photoemission Spectrum of the Valence Bands of Gold. Phys. Rev. B 1972, 5, 4709. [CrossRef]

44. Penn, D.R. Quantitative chemical analysis by ESCA. J. Electron Spectrosc. Relat. Phenom. 1976, 9, $29-40$. [CrossRef]

45. Klementiev, K.V. Webpage CELLS-ALBA. Available online: https://intranet.cells.es/Beamlines/CLAESS/ software/VIPERmanual220.pdf (accessed on 2 May 2017).

46. Ankudinov, A.L.; Ravel, B.; Rehr, J.J.; Conradson, S.D. Real space multiple-scattering calculation and interpretation of X-ray-absorption near-edge structure. Phys. Rev. 1998, 58, 7565-7576. [CrossRef]

(C) 2017 by the authors. Licensee MDPI, Basel, Switzerland. This article is an open access article distributed under the terms and conditions of the Creative Commons Attribution (CC BY) license (http:/ / creativecommons.org/licenses/by/4.0/). 